REFLECTIVE PIECE

\title{
Promoting an Ethical Economics Classroom Through Partnership
}

\author{
Simon D. Halliday, Economics Department, Smith College, MA, USA
}

Contact: shalliday@smith.edu

In teaching economics, the instructor scaffolds what they teach on an implicitly assumed or explicitly recognized ethical vision. Such a vision holds true even as economists often separate "positive economics" from "normative economics," claiming positive economics finds its basis in data and theory whereas normative economics concerns the ought or ethical statements that data or theory may imply (Davis, 2016). Economics, furthermore, suffers from lack of diversity: from white men constituting the majority of researchers and teachers, to textbooks that fail to show the diverse range of real people participating in the economy (Aerni, Bartlett, Lewis, McGoldrick, \& Shackelford, 1999). In contrast, students taking economics at the undergraduate level, and particularly at Smith College, a liberal arts college in Massachusetts where I teach as an assistant professor, are especially diverse. I believe, therefore, that the choices about what an instructor teaches in a course and how that instructor does so are ethical choices in teaching. These choices cohere around an instructor's pre-analytic vision of what a course ought to achieve, how the instructor models for students what constitutes good economics, or how diverse voices improve economics (Schumpeter, 2006/1954). ${ }^{1}$

Experience informs my ethical vision about my classes. As a student, my understanding of economics drew on my studies and life outside my South African classroom. In volunteering, I witnessed inequality and poverty made manifest through classrooms lacking textbooks or wellkept desks; I protested for access to anti-retroviral medication for people living with HIV/AIDS; I engaged in action to recognize the positive role of LGBTQ folks and people of color on campus and in wider society. My context informed my understanding of economics and my personal ethics. Though some of my students may experience concerns over unemployment, poverty, and healthcare, in the relatively wealthier climes of Western Massachusetts, many of my students remain distanced from the immediacies of poverty, policy, and production.

When considering my ethics in teaching, therefore, I ask myself many questions. ${ }^{2}$ What ought I to do to recognize and correct for inequalities among students? How should representation-in gender, ethnicity, and so on-affect what examples and data I use? How can I recognize and alleviate students' mental health concerns? Can I make concrete and clear the challenges economics confronts and how data address such challenges? Can assessment practices alleviate within-classroom inequalities generated by the high-school-to-college

CC-BY Licence 4.0 This is an Open Access article distributed under the terms of the Creative Commons Attribution License 4.0 International (https://creativecommons.org/licenses/by/4.0/), which permits unrestricted use, distribution, and reproduction in any medium, provided the original work is properly attributed. 
pipeline and facilitate student flourishing? Can my students and I find ways to promote compassion and wellness? Does my teaching ultimately reflect my ethical vision?

Maintaining a course that reflects one's ethical vision requires effort, accountability, and perseverance. How could I hold to these commitments when the stresses of the semester felt overwhelming? I argue that sharing the burden for maintaining an ethical classroom can be done through a student-faculty partnership and that learning improves as a result (Cook-Sather, Bovill, \& Felten, 2014). In Fall 2018, I was offered a student-faculty partnership during my first time teaching the department's introductory statistics and econometrics class, during which three guiding principles grew from my questions and ethical vision:

1. to emphasize individual and communal learning with deliberate practice toward growth and integrity,

2. to facilitate student practices that would promote metacognition and mastery, and

3. to understand the roles of diversity and representation by confronting new data and worked examples.

I was partnered with a student, Emily, who was a double major in education and sociology. We kept the guiding principles in mind as we considered my pedagogy. Partnering with Emily improved my ideas and teaching, while also allowing me space to grow and flourish in future teaching. In regularly meeting with, holding myself accountable to, and witnessing the commitment of my partner, I felt more capable of maintaining the practices that adhering to my ethical vision required of me. I argue, therefore, that faculty-student partnerships-while improving pedagogy-reinforce and hone a shared ethical vision.

\section{PARTICIPATORY POLLING AND PAIRING}

I based my pedagogy on evidence from the learning sciences on facilitating deliberate practice, retrieval learning, spacing, interleaved practice, and metacognition. Retrieval involves asking students questions to recall recently learned material, thereby getting a student who might otherwise think they "understood" an idea to apply that knowledge; spacing requires a student to space their practice over time; and interleaving requires testing different ideas simultaneously (Brown, Roediger III, \& McDaniel, 2014).

Together, these practices facilitate a student taking ideas from short- or medium-term memory and embedding them in medium- or long-term memory. Using such practices alongside reflection exercises can improve a student's metacognition-their ability to think about their thinking. My partner and I therefore focused on research-based practices. We used Poll Everywhere to ask multiple-choice questions and to produce word clouds. For multiplechoice questions, students would see a question projected on the screen at the front of the class and answer the question privately. They would then talk to classmates in a think-pairshare activity, after which they could change their answer. I would conclude by projecting a graph of the answers students gave and facilitating an in-class discussion (Boyle \& Goffe, 2018). 
Figure 1. A word cloud poll from my first class asking about attitudes to statistics

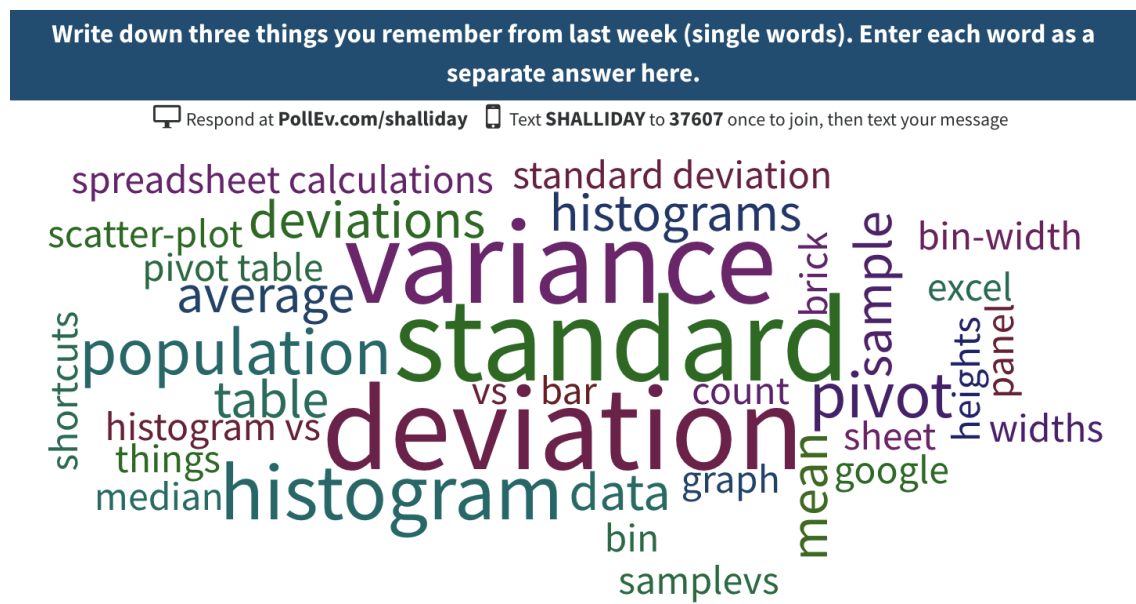

Straightforward though the activity may seem, Emily showed me how to improve it. During the think-pair-share, she mapped the classroom to see patterns of student behavior (Abbot, Cook-Sather, \& Hein, 2014). In mapping the classroom, she identified problematic group behaviors: students did not participate in diverse groups, students did not talk enough, and students appeared uncertain about time constraints. She recommended I intervene as follows: make the student groups explicit so a student had to talk to a classmate and reflect, mix groups so students experienced more diverse opinions rather than talking only to friends, and specify time constraints to empower students to work to time.

Following Emily's advice, I changed my pedagogy to increase transparency and explicitness. I created named groups where students would participate in different groups at different times, and addressed uncertainty by explicitly stipulating time. ${ }^{3}$ These small, iterative changes ensured that students engaged with each other better and improved their learning. The students, furthermore, acknowledged how my partner and I collaborated to continually improve the class. Such changes do not come without anxiety, however. Knowing students dislike change led me to worry about the consequences of these changes, but Emily re-assured me and supported me even when some students voiced passing discontent. Our ongoing discussions demonstrated how partnership involves more than academic discussion and analysis, but also a kind of collaborative care work that supports student and instructor alike.

\section{MASTERY, METACOGNITION, AND MENTAL WELLNESS}

In assessing student learning, I wanted to ensure students exerted effort to engage with the material while recognizing that they learn at different rates, enter classes with different levels of preparation, and may need to improve their metacognition. I framed my intentions around specific assessment and learning practices and, as many students feel anxiety around learning and grades, I investigated methods to alleviate anxiety and to promote mental wellness.

Students had two midterm exams and a final exam. Upon receiving their graded exams, students completed an exam wrapper (Ambrose, Bridges, DiPietro, Lovett, \& Norman, 2010). 
Exam wrappers ask students to reflect on how much time they dedicate to studying, to think about their study methods, and to assess whether their methods worked. After the exam wrapper, I offered students who had achieved fewer than the median number of points the opportunity to engage in a learning activity to improve their points up to a maximum of the median.

The learning activity had two parts. First, students had to re-answer the questions they got incorrect, for which they could talk to classmates, use their notes, and check the textbook. Second, students had to reflect on their answers, explaining why they got the incorrect answer the first time and how new answers were more correct. The learning activity facilitated deliberate practice and aided metacognition. ${ }^{4}$

Such an attitude towards assessment explicitly requires a professor to prioritize learning as mastery, rather than learning as credentialism (Kulik, Kulik, \& Bangert-Drowns, 1990). Research in the cognitive, learning, and social sciences around competition and extrinsic versus intrinsic incentives demonstrates how students may undermine their learning if they view the outcomes as competitive and out of reach. Thus, providing opportunities to reflect on failure and to think about change encourages students to adopt a growth mindset, which correlates with later success (Paunesku et al., 2015). These strategies, moreover, tend to benefit students who would normally fall in the lower part of the grade distribution, therefore according with my intention to address pre-existing inequalities among students.

Figure 2. A crude model of learning: Students may be of different types in a class, where some learn quickly earlier, some learn quickly later, or some learn roughly linearly. But exams occur regardless of a student's pace of learning and therefore may penalize those who learn more quickly later in a course.

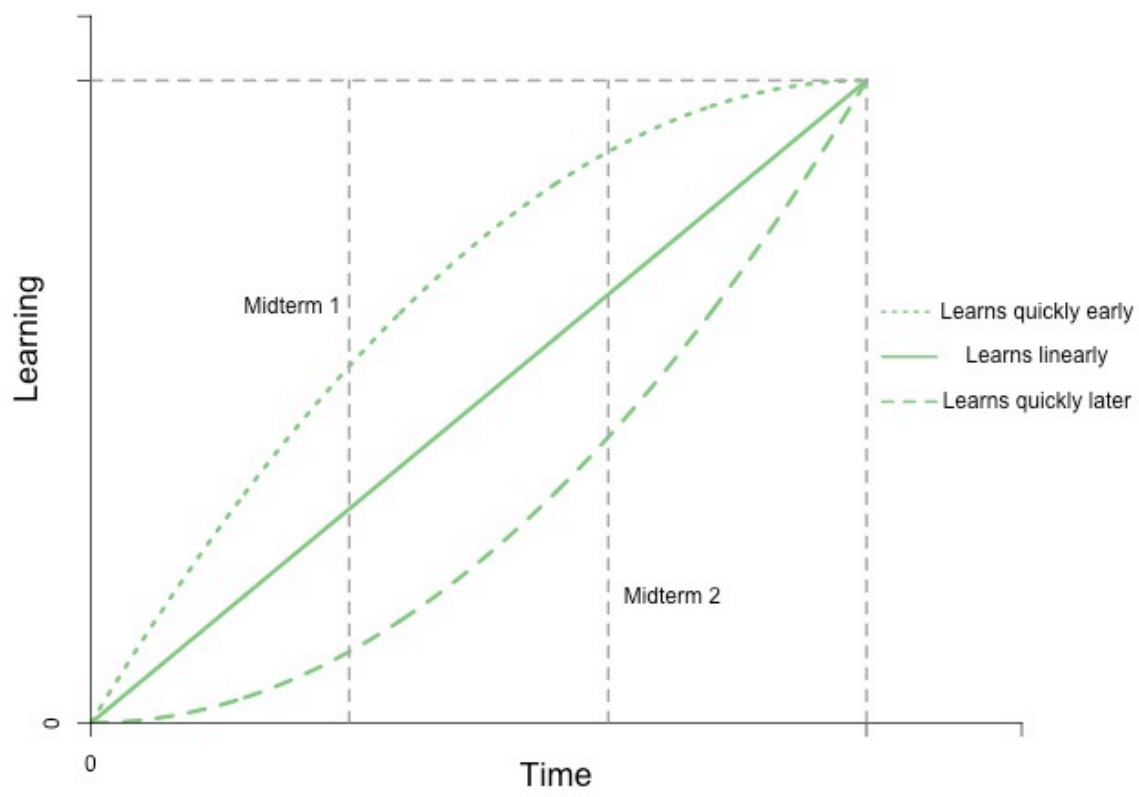

Though I began the class with the learning activity in mind, Emily encouraged me to be more intentional in explicitly discussing my model of learning with the students. She suggested I 
graph how I saw students' learning rates differing, and explain why I believed an approach like mine benefits students and addresses learning differences, while not disadvantaging students who have done well already (see Figure 2). My partner urged me to recount personal stories of failure where reflecting allowed me to improve, and to discuss why I engaged in the practices I did to level the playing field for students from diverse backgrounds, such as first-generation college graduates like myself (Broda et al., 2018). My partner also asked me to share why my ethical vision motivated me to teach in the way I did.

Emily's recommendations helped make my strategies more transparent, which improved student understanding of my teaching methods and modeled how students can engage in their learning with compassion. Though a student might have begun by feeling alienated from mastery learning, my recognition of concerns over grades and my intent to alleviate anxiety meant they engaged more fully with the material. Hearing that I had struggled helped them see that professors have failed too and have worked hard to achieve success. I would not have been as open with my students nor as clear about my methods without Emily's help. ${ }^{5}$ In writing their final course reflections, many students highlighted how compassion and personal identification motivated them to study, engage with learning, and work to help themselves and their classmates. ${ }^{6}$

Two other insights arose from my partner's and my engagement in assessment. First, Emily and I disagreed about the best ways to assess my students. Emily argued that I should use untimed assessments (as is more common in her classes), but my colleagues who teach this course do so with timed exams, and departmental or disciplinary norms are important constraints in one's practice. Second, as a junior faculty member and given my path to tenure, I am constrained in both how I can innovate and the extent of my innovation. Deviating too greatly from departmental assessment practices would be risky for me. Combining exam wrappers, my reflective learning activity for students who obtained fewer points, and discussing these practices in class provided us a way to reconcile our different positions and find a common ground while being within departmental and college practice. Emily also came to recognize the challenges junior faculty face in the academic hierarchy, which gave her greater insights into the functioning of higher education and her own college classes.

\section{DIVERSIFYING DATA ANALYSIS}

I wanted to equip my students to use and analyze data with the values of autonomy, integrity, and transparency. ${ }^{7}$ Doing so required that I teach my students about reproducibility: ensuring that one's methods and data analysis can be reproduced by independent third parties who have no vested interests in one's work. We therefore adopted a version of the TIER protocol (i.e., Teaching Integrity in Empirical Research, see Ball \& Medeiros [2012]). Students use the protocol and learn how to structure folders, write documents, and maintain program files. If a student follows the protocol, then other researchers can read and reproduce their work.

While highlighting transparency and integrity, I also wanted to value autonomy: to ensure that students as citizens could access and verify data analysis. Emily took on these values while upholding the importance of diversity in data and classroom discussion, and her commitment and insight improved my own as we came to know each other better during the semester. 
During our weekly meetings, we spoke about social inequalities in the curriculum and worked on ways to bring more diverse data and problems into the classroom. We used data from three countries - the US, South Africa, and the UK-for final student reports and analyzed other publicly available data from many countries. We reproduced analyses that interested students because of topics that affect their lives, such as the minimum wage; had documents or data that students could access to reproduce the analysis; and diversified the examples my students saw. We covered a variety of topics, some of which I highlight below: ${ }^{8}$

- How do we understand gender, education and child health? We used data from the World Bank and GapMinder to understand child mortality, parental education, and income for low income, middle income, and wealthy countries.

- How do race, gender, education, and income correlate in unequal societies? Using the National Income Dynamics Study from South Africa, we repeatedly engaged with questions of historical inequality (i.e., apartheid) and its effects on differential welfare and educational achievement.

- Does raising the minimum wage affect employment? Students who complete an introductory economics course are typically taught that, in theory, a minimum wage causes unemployment and excess demand for jobs in the industry. But what does it mean for evidence to conflict with theory (Card \& Krueger, 2000)?

Continually talking with Emily, I became more conscious of examples I taught or that students would read, many of which were separated from student experiences, or which might reinforce negative stereotypes. For example, in our textbook the author employs a (manufactured) example where women spend more money than men, and in so doing promotes stereotypes about buying behavior and gender. I created new examples from the High School and Beyond dataset on test scores and gender, where gender may or may not predict test scores, but with which students more readily identify. I hoped my inclusion of other examples might qualify what was covered in the textbook and expose students to new ideas and data. Having a partner who reminded me of my ethical vision and provided support helped me to maintain my discipline in developing original content.

\section{CONCLUSION}

Instructors enter their classrooms with an explicit or implicit ethical vision about education and the ways in which their pedagogy brings their vision to reality. A student-teacher partnership provides a structured way to surface, revise, refine, and implement an instructor's vision. The student partner can provide shared responsibility for the instructor's ethical vision, practical guidance from a student perspective about how to alter and implement a shared ethical vision in the classroom, and accountability as someone who moves from student to peer through partnership and shared endeavor.

\section{ACKNOWLEDGEMENTS}

I would like to acknowledge the mentorship of Floyd Cheung, the director of the Sherrerd Center for Teaching and Learning at Smith College, and the tireless work of my student partner Emily Olmos-Govea. 


\section{NOTES}

1. I acknowledge my positionality as a cisgender, white, immigrant male instructor and this acknowledgment constitutes a part of my ethical vision and informs my attempts at curricular reform.

2. I shall not exhaustively define what constitutes my vision but hope that the questions reveal some of its aspects. I take for granted that cultivating autonomy and critical thinking among my students plays a role in my vision; see, e.g., Garnett (2016). Also, I consider this ethical vision as somewhat separate from the stance of practicing virtue in the classroom as outlined by Binder (2016), though her argument that one needs fortitude remains true of my experience.

3. I would tell students, "You are now going to partner with your Group [X]." Though making groups explicit improved engagement, the classroom was ill-suited to students moving around regularly, showing the ways in which architecture affects pedagogy.

4. This task did not come without tradeoffs: already successful students often wanted the solutions to the exams as soon as possible to reflect on their learning, but I could not distribute solutions as early as normal to facilitate the reflective practice for students who wished to improve their grades. I hope to improve how I manage such student expectations.

5. Indeed, diversity training at another institution saw minority students in particular benefit from recounting personal stories and asking about personal details and struggles, (see Oliver, 2018).

6. I used course stories, a reflective writing practice that students completed at the end of the semester. See, for example, Brewer and Jozefowicz (2006) for using reflective writing in economics courses.

7. Allgood and Bayer (2016) argue that being able to analyze data should be viewed as a "core competency" of a student graduating with an economics major.

8. It being the first time I taught the course, my endeavors were also constrained by time: deriving new examples and analyzing data in accessible ways is hard and time consuming.

\section{NOTE ON CONTRIBUTOR}

Simon D. Halliday is an assistant professor of economics at Smith College. He works in economics education and behavioral economics.

\section{REFERENCES}

Abbot, S., Cook-Sather, A., \& Hein, C. (2014). Mapping classroom interactions: A spatial approach to analysing patterns of student participation. To Improve the Academy, 33(2), 131-152. https://doi.org/10.1002/tia2.20014

Aerni, A. L., Bartlett, R. L., Lewis, M., McGoldrick, K., \& Shackelford, J. (1999). Toward a feminist pedagogy in economics. Feminist Economics, 5(1), 29-4.

https://doi.org/10.1080/135457099338139 
Allgood, S., \& Bayer, A. (2016). Measuring college learning in economics. In R. Arum, J. Roksa, \& A. Cook (Eds.), Improving Quality in American Higher Education: Learning Outcomes and Assessments for the 21st Century (pp. 87-134). San Francisco: Jossey Bass.

Ambrose, S. A., Bridges, M. W., DiPietro, M., Lovett, M. C., \& Norman, M. K. (2010). How learning works: Seven research-based principles for smart teaching. San Francisco: Jossey Bass.

Ball, R., \& Medeiros, N. (2012). Teaching integrity in empirical research: A protocol for documenting data management and analysis. The Journal of Economic Education, 43(2), 182-189. https://doi.org/10.1080/00220485.2012.659647

Binder, C. (2016). Practicing virtue in teaching and learning. Teaching and Learning Together in Higher Education, 1(18), 5. Retrieved from https://repository.brynmawr.edu/tlthe/vol1/iss18/

Boyle, A., \& Goffe, W. L. (2018). Beyond the flipped class: The impact of research-based teaching methods in a macroeconomics principles class. AEA Papers and Proceedings, 108, 297-301. https://doi.org/10.1257/pandp.20181052

Brewer, S. M., \& Jozefowicz, J. J. (2006). Making economic principles personal: Student journals and reflection papers. The Journal of Economic Education, 37(2), 202-216. https://doi.org/10.3200/JECE.37.2.202-216

Broda, M., Yun, J., Schneider, B., Yeager, D. S., Walton, G. M., \& Diemer, M. (2018). Reducing inequality in academic success for incoming college students: A randomized trial of growth mindset and belonging interventions. Journal of Research on Educational Effectiveness, 11(3), 317-338. https://doi.org/10.1080/19345747.2018.1429037

Brown, P. C., Roediger III, H. L., \& McDaniel, M. A. (2014). Make it stick: The science of successful learning. Cambridge, MA: Harvard University Press.

Card, D., \& Krueger, A. B. (2000). Minimum wages and employment: A case study of the fastfood industry in New Jersey and Pennsylvania: Reply. American Economic Review, 90(5), 1397-1420. https://doi.org/10.1257/aer.90.5.1397

Cook-Sather, A., Bovill, C., \& Felten, P. (2014). Engaging students as partners in learning and teaching: A guide for faculty. San Francisco: Jossey Bass.

Davis, J. B. (2016). Economists' odd stand on the positive-normative distinction: A behavioral economics view. In G. F. DeMartino \& D. N. McCloskey (Eds.), The Oxford handbook of professional economic ethics (pp. 266-290). Oxford: Oxford University Press.

Garnett, R. F. J. (2016). Ethics and learning in undergraduate economics education. In G. F. DeMartino \& D. N. McCloskey (Eds.), The Oxford handbook of professional economic ethics (pp. 266-290). Oxford: Oxford University Press.

Kulik, C.-L. C., Kulik, J. A., \& Bangert-Drowns, R. L. (1990). Effectiveness of mastery learning programs: A meta-analysis. Review of Educational Research, 60(2), 265-299. https://doi.org/10.3102/00346543060002265

Oliver, P. (2018). About taking criticism. SocArxiv. https://doi.org/10.17605/OSF.IO/GVCMK

Paunesku, D., Walton, G. M., Romero, C., Smith, E. N., Yeager, D. S., \& Dweck, C. S. (2015). Mind-set interventions are a scalable treatment for academic underachievement. Psychological Science, 26(6), 784-793. https://doi.org/10.1177/0956797615571017 Schumpeter, J. A. (2006). History of Economic Analysis. Routledge. (Original work published 1954). 